\title{
ROLE OF GLUTATHIONE IN THE MULTIDRUG RESISTANCE IN CANCER
}

\author{
Ewa KARWICKA
}

Biochemistry and Biopharmaceuticals Department, National Medicines Institute

DOI: $10.2478 / \mathrm{v} 10052-010-0006-6$

Summary: Multidrug resistance is the main problem in anticancer therapy. Cancer cells use many defense strategies in order to survive chemotherapy. Among known multidrug resistance mechanisms the most important are: drug detoxification inside the cell using II phase detoxifying enzymes and active transport of the drug to the extracellular environment. Cancer cells may be also less sensitive to proapoptotic signals and have different intracellular drug distribution, which makes them more resistant to anticancer drugs. Role of glutathione in multidrug resistance is the object of interest of many scientists, however, defining it's function in these processes still remains a challenge. In this paper, properties of glutathione and it's role in multidrug resistance in cancer cells were described.

Key words: glutathione, glutathione-dependent enzymes, transport, MRP, MDR, multidrug resistance, cancer, drug resistance

\section{INTRODUCTION}

In spite of a tremendous advance in medicine and the improving understanding of neoplastic diseases, the multidrug resistance (MDR) phenomenon still remains the main issue preventing effective therapy. Multidrug resistance, both primary - innate and secondary - acquired in the course of therapy, depends on many factors. Multidrug resistance uses the natural properties of the cells for adaptation to the protection against anticancer treatment. Biological functions, which are beneficial for normal cells, may contribute to multidrug resistance in the case of neoplastic transformation. In fact, this phenomenon represents a metabolic condition of cancer cells, which use a number of 
resistance mechanisms to survive chemotherapy. Among the known mechanisms of drug resistance, drug detoxification using phase II antioxidant enzymes, and active drug efflux from the cells into the external environment are the most important. The synergic effect of these two mechanisms contributes to the occurrence of the MDR phenotype in response to the action of multiple chemotherapeutics [35]. In addition, cancer cells exhibit a reduced sensitivity to oxidative stress and proapoptotic signals, hence being more resistant to anticancer drugs used in therapy.

The function of glutathione in the multidrug resistance mechanism is the object of interest for researchers worldwide; however, it is difficult to determine the role of this compound in the specific processes leading to cell resistance to therapy. In this article, we present the basic physiological properties of glutathione and their role in the phenomenon of multidrug resistance of cancer using selected examples.

\section{PHYSIOLOGICAL PROPERTIES OF GLUTATHIONE}

Glutathione, chemical name $\gamma$-glutamylcysteinylglycine ( $\gamma$-glu-cys-gly), is a biologically active thiol tripeptide, which is present in nearly all prokaryotic and eukaryotic cells. It participates in the basic physiological processes including: protection against oxidation, redox reactions, biosynthesis of DNA, proteins and leukotrienes, as well as neural conduction and neuromodulation processes. Moreover, glutathione plays an important role in the regulation of metabolic pathway activity, and cellular growth and differentiation.

A special property of glutathione is its solubility both in water and lipids, enabling extensive distribution in the body and a broad spectrum of action. A typical feature in its molecular structure is the presence of an atypical isopeptide bond between the cysteine and glutamate residues, as well as the presence of the thiol group (-SH) belonging to the cysteine residue to which the biological functions of the peptide are directly related.

Glutathione may have several forms in the cell: reduced (GSH), oxidised (GSSG), S-nitrosoglutathione (GSNO), and mixed disulphides of glutathione and proteins.

GSSG is formed as a result of a two-electron reaction of dehydrogenation of the GSH thiol groups (Fig. 1). This may be an enzymatic transformation with glutathione peroxidase in the presence of NADPH. The reactivity of the GSH molecule also allows direct, non-enzymatic reduction of the oxidised molecules. In physiological conditions, GSSG is transformed to the reduced form by dihydrolipoate or glutathione reductase, with NADPH as a coenzyme. 

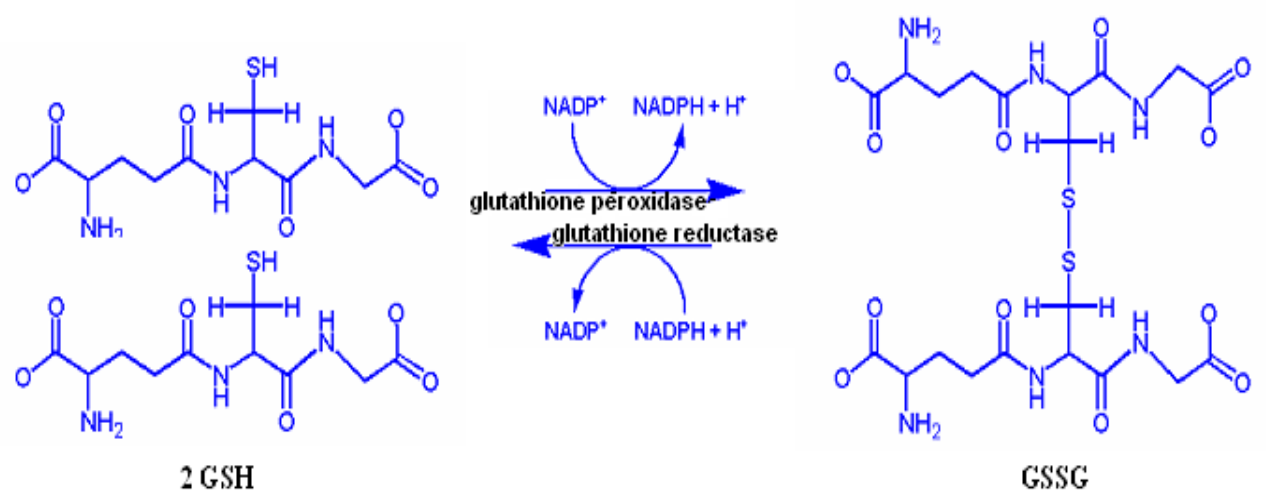

FIGURE 1. Transforming forms of glutathione

Most of the cellular glutathione is GSH, whereas the GSSG form usually represents about $1 \%$. Nearly $90 \%$ of cellular GSH is in the cytosol, and the remaining $10 \%$ in the mitochondria, with a small amount in the endoplasmatic reticulum. At the latter location, due to the physiological functions performed, oxidised glutathione represents about 30-50\% [22].

Glutathione has the function of a thiol buffer enabling to maintain the appropriate oxidoreductive status in the cell. It is measured as the concentration ratio of the GSH/GSSG forms, denoted with the R symbol. Increased amount of GSSG indicates oxidative stress that may be associated with a disease, mental stress, body aging, increased physical exercise or direct effect of toxic compounds [7, 53, 56, 69]. In physiological conditions, the $\mathrm{R}$ coefficient value in the hepatocytes is $150-400$, whereas during severe oxidative stress it can drop down to as low as 2 [22]. It was found that oxidative stress and the related damages play an important role in the early stages of cardiovascular diseases, neurodegenerative diseases and neoplastic transformations [19].

Glutathione synthesis only occurs intracellularly. Exogenous glutathione has no use in the treatment - it cannot be administered with food because it is digested in the gastrointestinal tract; moreover, it practically does not pass through the cellular membranes and poorly crosses the blood-brain barrier. Methyl, ethyl, and propyl glutathione monoesters, due to their hydrophobic nature, can be easily transported through the cell membranes; however, they have been found to have a nephrotoxic effect, which prevents from using them in the treatment of glutathione deficits. The cell glutathione level can only be increased by providing its structural precursors. Cysteine, due to the presence of the sulphur atom, usually represents the synthesis-limiting 
factor. The main site of glutathione synthesis in the body is the liver, due to the ability of hepatocytes to transform methionine into cysteine by demethylation. However, the use of products containing cysteine or bound cysteine is limited due to strong neurotoxic properties of this amino acid [6].

Glutathione biosynthesis and biodegradation has been presented by Meister as a part of the metabolic pathway referred to as $\gamma$-glutamyl cycle (Fig. 2). The molecule synthesised inside the cells is degraded in the extracellular space. Glutathione concentration in the cell is about 500 times higher than in the external environment, and it is usually in the range of 0.1 to $10 \mathrm{mM}$ [60].

Glutathione biosynthesis occurs in the cellular cytosol from L- $\alpha$-glutamate (glu), L- $\gamma$-cysteine (cys) and glycine (gly) in a two-stage reaction, with involvement of $\gamma$-glutamylcysteine synthetase $(\gamma$-GCS) and glutathione synthetase $(\gamma$-GS) [36]. This process does not require the RNA matrix. Only minor amounts of glutathione reach the external environment in unchanged form. Most glutathione leaving the cell is oxidised glutathione and glutathione in the form conjugated with other particles.

Glutathione in the extracellular space does not directly cross the cell membranes but it is decomposed into individual amino acids which then bind together again inside the cell [20]. In the first stage of biodegradation, the isopeptide bond between the $\gamma$-carboxyl group of glutamate and the amino group of cysteine is hydrolysed with involvement of $\gamma$-glutamyltransferase $(\gamma-G T)$, also referred to as glutathionase. The formed cysteinylglycine is further hydrolysed to glycine and cysteine, whereas the $\gamma$-glutamyl residue is transferred onto an amino acid acceptor to form $\gamma$-glutamylamino acid which returns to the cell. In the next stage, $\gamma$-glutamylamino acid is transformed into free amino acid and 5-oxoproline which is further transformed into glutamate. The amino acids formed in the process of enzymatic degradation of glutathione can be re-used for biosynthesis of new molecules. The main activity of the $\gamma$-GGT enzyme is to recover cysteine from the GSH molecules removed from the cell to re-build it into GSH or newly synthesised proteins. The enzyme activity shows a negative feedback in response to GSH level changes in the cytosol [33].

The key enzyme limiting glutathione biosynthesis is $\square$-glutamylcysteine synthetase $(\gamma$-GCS), which shows a negative feedback in response to the peptide concentrations in the cytosol. $\gamma$-GCS activity and the availability of intracellular cysteine are two main elements regulating glutathione homeostasis in the cell. Moreover, glutathione levels depend on the activity of other enzymes including $\gamma$-glutamyl transpeptidase $(\gamma-\mathrm{GT})$, amino acid transporters, glutathione synthetase (GS), glutathione peroxidase (GPX) and glutathione reductase (GR). Mutations of the genes encoding 5 out of 6 enzymes of the $\gamma$-glutamyl pathway, glutathione synthetase, $\gamma$-glutamylcysteine synthetase, $\gamma$-glutamyl transpeptidase, 5 -oxoprolinase and 


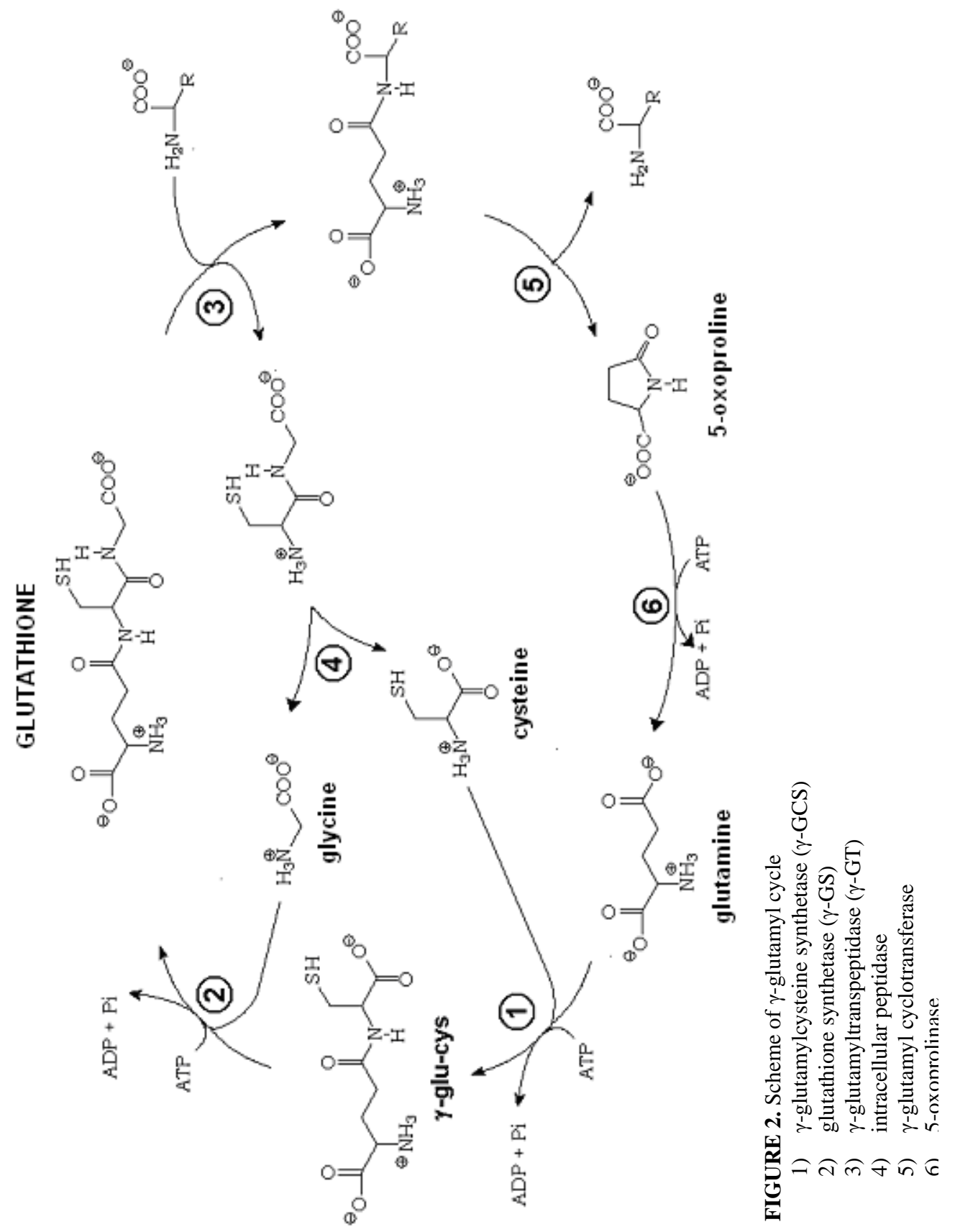


dipeptidase cause severe disorders of glutathione metabolism; however, they are very rare in humans. The complications usually associated with glutathione metabolism disorders include haemolytic anaemia, metabolic acidosis, 5-oxoprolinuria, central nervous system damage, and chronic bacterial infections [52].

\section{GLUTATHIONE AS AN ANTIOXIDANT}

Maintaining the physiological oxidoreductive balance, expressed in the cell by the changes in prooxidant and antioxidant activity, is the key problem in the regulation of the fundamental metabolic transformations, as well as the processes related to cell life and proliferation [2, 36]. Glutathione is one of the most important compounds of the body's antioxidant barrier. Its presence is necessary for maintaining the oxidoreductive balance and to counteract the consequences of oxidative stress. GSH is a factor that: reduces the endogenously formed reactive oxygen species (ROS), protects the thiol groups of proteins, participates in the repair processes of proteins, nucleic acids and lipids. Another significant function of glutathione is the ability to regenerate other small-molecular antioxidants such as, for example, ascorbate and tocopherol [44, 57].

Oxidative stress results from accumulation of reactive oxygen species, such as hydrogen peroxide, superoxide anion radical and hydroxyl radical, formed endogenously or as a result of external factors, in the cell. The antioxidant defence and the regulation of the cellular oxidoreductive status are based on continuous processes of conversion of the reduced glutathione form GSH into the oxidised form GSSG and vice versa. GSH reacts with the ROS and is oxidised to GSSG, then it is transformed into the reduced form again. However, acute oxidative stress can reduce the cell's ability to reduce GSSG to GSH, and as a result, GSSG may accumulate in the cytosol. To maintain the oxidoreductive balance, GSSG is removed to the extracellular environment or it may react with sulfhydryl groups of proteins, forming mixed disulphides of proteins and glutathione. Both processes lead to a reduction of the pool of available glutathione in the cell and reduce its defensive abilities [33].

In addition to neutralising free oxygen radicals, glutathione has an important protective function as it prevents or reduces the toxicity of many substances. The main role of glutathione is to inactivate chemotherapeutics before they reach their target, and to participate in their transport outside the cell.

GSH binding to a xenobiotic or its metabolite leads to the formation of conjugates which are then removed from the cell. The conjugate formation process may occur spontaneously or it may be catalysed by cellular glutathione S-transferases. 
Like in the case of ROS detoxification, the amount of cellular glutathione is then reduced. Paradoxically, in some cases cell exposure to oxidative stress has a reverse effect of increasing GSH levels. In experiments involving rat hepatocytes exposed to the effect of N-nitrosodimethylamine (NDMA), butylated hydroxyanisole and nitrofurantoin, an increase in intracellular glutathione levels was seen $[16,25,58]$. The phenomenon of glutathione synthesis upregulation is caused by the stimulation of $\gamma$-GCS expression and it is most likely an adaptive mechanism of defence against the effects of reactive oxygen species.

Cancer cells resistant to the effects of drugs were also found to have higher glutathione levels compared to healthy cells as a result on increased expression of the $\gamma$-GCS encoding gene. GSH participates in the detoxification processes of, for example, platinum-containing drugs, alkylating agents (melphalan), anthracyclines (doxorubicin, daunorubicin), and arsenic compounds [17, 28]. Providing a reductive environment by glutathione also favours the repair processes of DNA damages caused by the drugs. GSH activity allows multidirectional complex protection and improving the survival of cancer cells exposed to the effect of chemotherapeutics.

\section{Glutathione and protein metabolism}

Glutathione has the ability to react with the thiol groups of cellular proteins, forming mixed disulphides (protein-S-S-glutathione) in the process referred to as S-glutathionylation. This reaction ensures protection against irreversible oxidation of kinases and protein phosphatases, AP-1 and NF-kB transcription factors, proteins from the "chaperon" family, and extracellular haemoglobin. The phenomenon is of special importance in the case of regulatory and antioxidant proteins because is allows maintaining their biological activity in the oxidative stress conditions [24].

In addition to the protective properties, glutathione can also participate in the activity regulation of proteins, e.g. receptors, protein kinases and some transcription factors, by affecting the thiol groups located in their active centres. Protein regulation by S-glutathionylation may depend on the position of the cysteine residue undergoing modification, and it may be either activation or inhibition. S-glutathionylation also occurs at the stage of post-translation modifications of proteins, during the formation of the tertiary structure, the formation of disulphide bonds, and protein folding in the endoplasmatic reticulum. GSSG participates in these processes as an oxidant of the -SH groups of cysteine residues. This reaction, catalysed by disulphide isomerase (PDI) leads to concomitant re-formation of glutathione in the reduced form (GSH). It has been shown that glutathione is involved in the protein biodegradation processes, both in the ubiquitination stage and in relation to proteasome activity. Through S-glutathionylation, glutathione mediates the inhibition of E1 and E2 protein activity; 
these proteins participate in the addition of the ubiquitin molecule to the degraded proteins. It has also been shown that glutathione in micromole concentrations activates the proteasome, and in millimole concentrations it may inhibit it [14].

\section{GLUTATHIONE-DEPENDENT ENZYMES AND DRUG-RESISTANCE}

The cell ability to maintain an adequately high glutathione level depends on the activity of various enzymes and metabolic pathways. Simultaneously, changes in GSH concentrations may affect the levels of enzymes for which it is a cofactor. For the cancer cells to achieve a phenotype typical for multidrug resistance, co-operation of many elements of the detoxification system is necessary.

In the first studies on the role of glutathione-dependent enzymes in multidrug resistance it has been shown that the achievement of multidrug resistance is associated with significant changes to the glutathione-dependent enzyme profile, and as a result, changes in reduced glutathione levels. Differences in concentrations of glutathione-dependent enzymes, GT, GST and GPX, were seen in two ovarian adenoma cell lines taken from a single patient: sensitive PE01, and after development of resistance to chlorambucil, cisplatin and 5-fluorouracil, PE04. In the drug-resistant line, a higher activity of all 3 enzymes and a higher level of reduced glutathione were seen compared to the sensitive line [29].

Experiments with factors inhibiting the activity of glutathione-dependent enzymes provided further information on their activity in drug-resistant cells. Many studies are currently ongoing to evaluate the possibility of using glutathione-dependent enzyme inhibitors as multidrug resistance modulators in targeted anticancer therapy.

Buthionine sulphoximine (BSO) blocks the activity of $\gamma$-GCS, the key enzyme in glutathione biosynthesis. BSO causes irreversible inhibition of glutathione synthesis and reduces glutathione levels in the cell by $90 \%$ over 24 hours. Mouse experiments involving murine ovarian cancer cells OVCAR-3 treated with melphalan have shown that the survival of mice simultaneously undergoing BSO therapy is higher by $72 \%$ compared to the control group [43]. Studies involving human cancer cells have shown that BSO therapy reverses the MDR phenotype by making the cancer cells sensitive to treatment with platinum compounds, alkylating agents, anthracyclines, and arsenic trioxide [3, 18, 28, 41]. In vitro studies have shown that even a partial inhibition of GSH synthesis increases the efficacy of treatment [28]. However, the use of BSO is limited due to its cytotoxic effect on the healthy cells in the body.

Cancer cell resistance is also associated with excessive activity of glutathione 
S-transferase (GST) co-operating with GSH [62]. Glutathione S-transferases are a family of enzymes catalysing the conjugation reaction of electrophilic substrates with the GSH molecules (Fig. 3). Seven classes of cytosol GST proteins are known in mammals, denoted as $\alpha, \mu, \pi, \tau, \sigma, \varepsilon$ and $\kappa$. The broad substrate range of GST results from both strong polymorphism and low specificity of the bond formed [64]. This property of GST allows metabolising and detoxification of many various substrates, both endogenous products of lipid peroxidation or DNA peroxides, and xenobiotics: carcinogens, impurities and drugs. GSTs from the $\mu$ and $\pi$ classes are also involved in the regulation of the apoptotic MAP kinase pathway, among other mechanisms, through the inhibition of the c-Jun kinase [1].

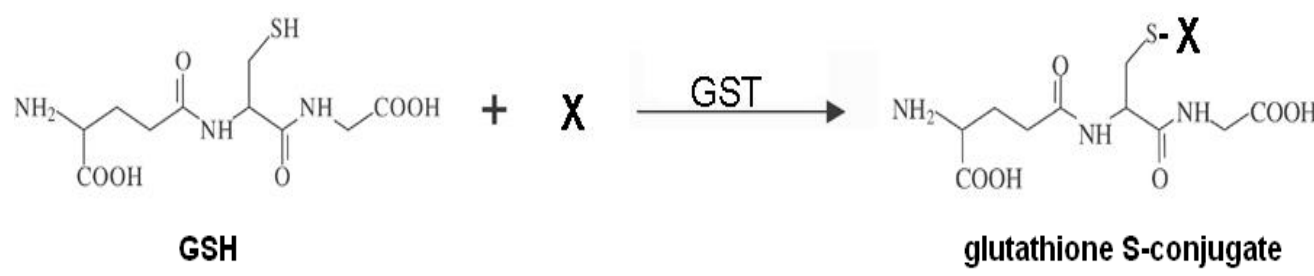

FIGURE 3. Conjugation of glutathione (GSH) with a xenobiotic molecule (X) catalysed by glutathione Stransferase (GST) (according to [62]).

GST overexpression, mainly in the $\pi$ class, has been seen in the cells of many tumours and it may also occur in other pathologies [60]. GST involvement in the MDR phenomenon is mainly based on the detoxification processes as well as inhibition of the MAP kinase pathway. It was found that this enzyme participates in detoxification of oxidative stress products such as lipid peroxidation products, acrolein or base propenals, and not, as it could seem, in detoxification of the drug itself. High level of GST activity is most likely the result of cell selection during oncogenesis, and not the direct cause of the MDR phenotype [60]. Experiments involving the use of a GST inhibitor - ethacrynic acid (EA) and BSO are being performed to identify the effects of simultaneous block of GSH synthesis and GST activity. Ethacrynic acid is a substrate analogue for GST from classes $\mu, \alpha$ or $\pi$, and it forms conjugates with glutathione. Double therapy using EA and BSO has been used in many cases to check the sensitisation of cancer cells to the treatment used.

GST is the main subject of studies concerning multidrug resistance in cancer; however, other enzymes participating in GSH synthesis and metabolism are also involved in the cell response to the effect of anticancer drugs. In the conditions of increased GST expression, increased levels of activity of other enzymes of the $\gamma$-glutamyl pathway, GPX and $\gamma$-GT, were seen. Selenium-dependent glutathione 
peroxidase, GPX, belongs to the $1^{\text {st }}$ line of the cellular antioxidant defence. GPX and glutathione play the central role in maintaining the oxidative balance during treatment with quinone drugs. It was found that GPX is responsible for the detoxification of free oxygen radicals and lipid peroxides generated in the detoxification processes of compounds such as doxorubicin, daunorubicin, mitomycin $\mathrm{C}$, diazoquinone and menadione. Changes in the enzyme activity levels have a significant effect on the activity and toxicity of these substances for the cells [15].

$\gamma$-glutamyltranspeptidase is a membrane enzyme involved in the regulation of cellular glutathione levels by uptake of this compound from the extracellular space. Its expression is upregulated in many types of human cancer; however, the enzyme levels are variable both between various cancer types and between various cells of the same cancer [45]. $\gamma$-GT expression is not the main mechanism on which drug resistance is based; however, it was shown that this enzyme is involved in maintaining the oxidoreductive balance, and that it affects the cell response to anticancer medication, mainly cisplatin and alkylating agents $[12,48]$.

\section{GLUTATHIONE INVOLVEMENT IN TRANSMEMBRANE TRANSPORT}

One of the basic mechanisms of drug resistance is transmembrane transport of compounds from the cytoplasm to the extracellular environment. The transport occurs with participation of proteins belonging to the $A B C$ transporter superfamily which have a common feature of an ATP-binding cassette. The first identified transporter from the $\mathrm{ABC}$ family, involved in multidrug resistance, was glycoprotein $\mathrm{P}(\mathrm{P}-\mathrm{gp})$.

Glycoprotein $P$ has been discovered in the course of studies of ovarian cancer in hamsters [23]. P-gp is a $170 \mathrm{kDa}$ protein encoded by the $m d r-1$ gene. It is common in many types of tissues, protecting them against the cellular metabolites, exogenous substances and their degradation products. P-gp shows a very low substrate specificity, and it prefers hydrophobic compounds, mainly cations. Initially, glycoprotein $\mathrm{P}$ was the only known transporter involved in the drug resistance phenomenon. The experiments performed in 1992, concerning drug-resistant cells of human small-cell lung carcinoma H69AR, in which no increased P-gp protein levels were detected, indicated the presence of another multidrug resistance protein, referred to as MRP (multidrug resistance-related protein) [11, 13]. Until now, 6 isoforms of the MRP protein have been identified in humans, described consecutively as MRP1 to MRP6 (ABCC1 to ABCC6), as well as MRP7 to MRP9 of poorly explained biological functions [59]. The molecular weight of MRP1 is about $190 \mathrm{kDa}$, it also differs from 
P-gp in its structure and mechanism of action. The MRP1 protein is present in nearly all tissues of the body, and its function is to remove toxic substances from the cells at the cost of energy obtained from ATP hydrolysis. The substrates preferred by the MRP1 protein include compounds from the organic anions group [10].

The physiological functions of MRP1 are related to the GSH/GSSG system-dependent detoxification processes. However, the interactions between GSH and MRP1 are complex. The mechanism of transport has not been fully explained in terms of using glutathione in this process. MRP1 does not transport the chemical substances in unchanged form; instead, it prefers their anion derivatives following conjugation with GSH, or glucuronate or sulphate molecules. GST, which catalyses the conjugation process, most likely has a synergic effect versus MRP1 [10]. However, in some cases the attempts to detect drug conjugates or their metabolites with GSH failed, suggesting that the transport of xenobiotics by the MRP1 protein can be stimulated by GSH also in the mechanism of co-transport, activation or facilitation of substrate binding to the transporter $[27,30,54]$.

The studies of correlation between the transport of xenobiotics and GSH from the cell have provided no clear results, thus not enabling to determine a single pattern of the transport mechanism. The issue whether glutathione is only a ligand for an endogenous substances or it is transported independently by the MRP, remains unclear. The fact that GSH shows weak affinity to the transporter makes the studies of the possible relationships rather difficult. The results of some studies indicate that direct transport of glutathione by the MRP is probable [50].

The early hypotheses regarding the MRP-dependent transport with glutathione assume the existence of 3 mechanisms (Fig. 4):

1. conjugate transport with the GSH;

2. transport in which no conjugates have been found but it has been shown that GST activity is required for the normal transport by MRP1;

3. transport of GSSG formed from the GSH as a result of enzymatic reduction of the molecule with involvement of glutathione peroxidase.

The conclusions from many studies allowed to develop a theoretical model of the MRP1/2 transporter activity in which the protein would have 2 binding sites: $G$ and $D$, differing in their affinity to GSH, and able to competitively bind an endogenous ligand $[5,46]$. As a result, depending on the glutathione and ligand concentration ratio:

a) both binding sites, $\mathrm{G}$ and $\mathrm{D}$, can be linked to glutathione,

b) the binding site $\mathrm{G}$ can be linked to glutathione, and the binding site $\mathrm{D}$ - to the ligand,

c) both binding sites, $\mathrm{G}$ and $\mathrm{D}$, can be linked to the ligand.

The two GSH binding sites would undergo simultaneous mutual activation. The above model explains the problems in detecting the conjugates of some substances 


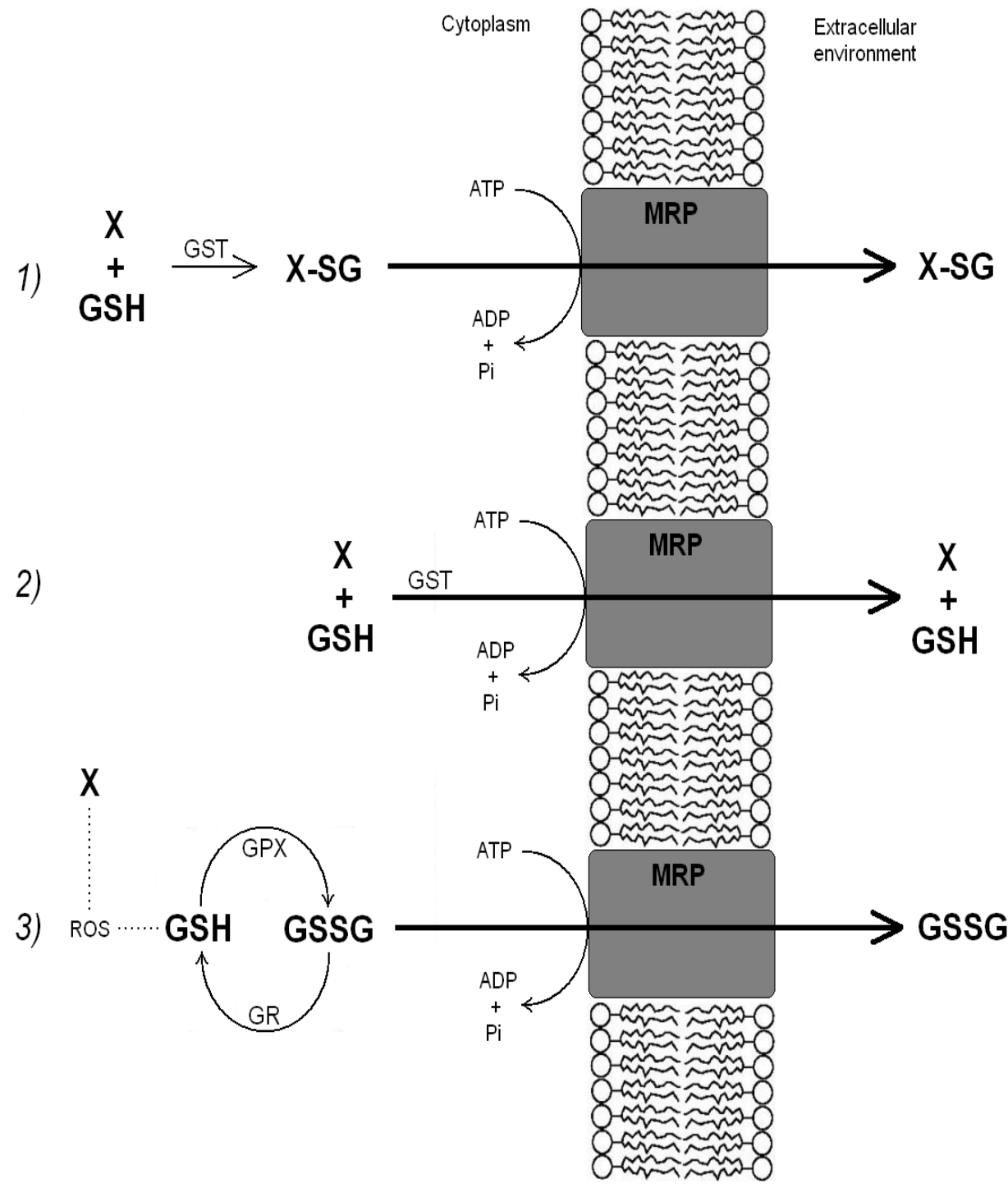

FIGURE 4. Hypotheses regarding MRP-dependent transport of drugs with glutathione.

1) transport of $\mathrm{X}-\mathrm{SG}$ conjugates of drug $(\mathrm{X})$ and glutathione (GSH),

2) transport, in which presence of conjugates X-SG were not proved - cotransport of drug and glutathione,

3) transport of oxidised glutathione (GSSG) formed as a result of reduction of reactive oxygen species (ROS) generated by drug, with glutathione. 
with glutathione. According to the above theory, they would show such high affinity to the MRP1/2 protein that glutathione would not be required for transport stimulation. It seems that GSH affinity to MRP also results from the differences in the structure of each MRP protein, affecting the substrate specificity of the transporters.

The activity of MRP1, MRP2 and MRP3 transporters contributes to the development of multidrug resistance of cancer cells.

MPR1 overexpression is seen in most types of cancer. This protein has the ability to directly transport drugs such as: anthracyclines (doxorubicin, daunorubicin), Vinca alkaloids (vincristine, vinblastine), etoposide or paclitaxel. A similar relationship was seen for natural, unmodified aflatoxin $B_{1}$. These results have been confirmed by the experiments aiming to evaluate the degree of transport inhibition of the $\mathrm{LTC}_{4}$ leukotriene, a natural competitive substrate for MRP1. In spite of a relatively low MRP1 affinity to this type of substances, their transport can be increased in the conditions of high GSH concentration in the cells [31, 39, 49].

In vitro tests have shown that the MRP2 protein contributes to resistance to cisplatin as well as other drugs: CPT-11, camptothecin SN-38, vincristine, vinblastine, etoposide and doxorubicin [8]. A relationship between the MRP3 protein expression and cell resistance to doxorubicin, vincristine, etoposide, cisplatin and teniposide has also been shown [26, 67]. All proteins, MRP1, MRP2 and MRP3, also contribute to resistance to short-term exposure to methotrexate (MTX) [21]. Gradual cell sensitisation is associated with the formation and cytoplasmatic accumulation of polyglutamated toxic derivative of methotrexate which is not a substrate for MRPs.

The processes of drug transport outside the cell are accompanied by extensive GSH efflux from the cell [47]. The cells devoid of the ability to synthesise MRP show high glutathione levels in the cytoplasm due to accumulation [4]. Despite significant losses of GSH, cancer cells with MRP protein overexpression show increased glutathione levels. The increased glutathione biosynthesis due to $\gamma$-GCS overexpression increases the survival of cancer cells and protects them against apoptosis [34].

Experiments involving the use of BSO have shown that in the case of some drugs, glutathione synthesis inhibition causes transport impairment and drug accumulation in the cell; as a result, cell sensitivity to the treatment increases. Melanoma cells which do not synthesise GSH show a higher sensitivity to arsenium trioxide [18]. It has been reported that the use of BSO can increase the efficacy of chemotherapy even in cells with MRP1 overexpression. However, the final effect depends on the cell line used and drug type. There is evidence that the effect caused by BSO is a direct result of GSH depletion, and not the effect on the MRP1 protein or the MRP-dependent transport [55]. The above hypothesis has been confirmed by studies in which it was found that in cells with MRP1 overexpression exposed to BSO, the administration of exogenous GSH in the form of ethyl ester increases the daunorubicin 
transport again and restores the MDR phenotype [65].

The contribution of the glutathione-dependent transport processes in the cancer multidrug resistance phenomenon has been confirmed by studies involving viral vectors. Cells from the NIH3T3T fibroblast line were transfected using cDNA of the genes encoding $\gamma$-GCS, GST and MRP. The study has been performed in various variants - both single transfections, double and triple combinations. It has been shown that in the mechanisms of resistance to a number of anticancer drugs used, the products of the above genes function in a coordinated way [40]. Simultaneous cotransfection with GST and GCS increased the resistance to doxorubicin, etoposide and vincristine more than with transfection with any single gene. Also GST co-expression along with MRP1 increased the resistance to treatment with chlorambucil, ethacrynic acid, etoposide and vincristine. Overexpression of all 3 elements of the system increases the drug resistance of the NIH3T3T cells to doxorubicin and etoposide treatment much more than overexpression of any 2 proteins or a single protein [40].

The combination of GCS and MRP1 had no effect on resistance increase compared to overexpression of the MRP1 protein alone. Cell resistance to chlorambucil and ethacrynic acid was at a similar level both with GST overexpression alone and in combinations, suggesting that in the case of these drugs, drug resistance is due to other mechanisms.

Similar experiments have shown that transfection of cancer cells with cDNA of GCS and MRP1 with GCS increases cell resistance to heavy metal compounds such as kadmium chloride, sodium arsenate and antimonium potassium tartrate [32, 61].

The $\gamma$-GCS, GST and MRP proteins most likely function together as a coordinated system of transport for many drugs used in chemotherapy. However, it is unknown if all types of drug-resistant cancers are capable of synthesising phase II detoxifying enzymes in quantities allowing the neutralisation of xenobiotics and elimination of these compounds from the cell at a level required for resistance. The transport of natural xenobiotics, excluding vincristin and daunorubicin, seems to occur via other mechanisms, independent of phase II enzymes [68].

\section{GLUTATHIONE ROLE IN APOPTOSIS}

The apoptosis phenomenon is directly related to the activity of proteins from the Bcl-2 family, and in particular Bcl-2 itself. Its role is to block cytochrome $c$ efflux from the mitochondria to prevent apoptosis.

The thiol buffer GSH/GSSG is one of the antioxidant systems preventing apoptosis. In the conditions of intensive membrane transport of GSH outside the cell, 
cytochrome $c$ release from the mitochondria was seen shortly before the induction of the apoptotic processes.

It has been shown that the cells that underwent cancer transformation show increased Bcl-2 expression, which increases their resistance to oxidative stress and apoptosis [9]. This phenomenon is an element of a very complex defensive strategy consisting in the disruption of balance between the pro- and antiapoptotic protein levels; it plays one of the more important roles in the drug resistance processes [51].

Based on the results of studies performed in recent years, a relationship between Bcl-2 activity and cell sensitivity to GSH synthesis disorders has been shown. It was found that cells which produce GSH and exhibit a particularly high resistance to BSO, also show increased Bcl-2 expression [63].

The studies of the relationship between Bcl-2 protein concentrations and cell glutathione concentrations have shown that with $\mathrm{Bcl}-2$ overexpression, glutathione concentrations increase nearly 3 times. The antiapoptotic properties of $\mathrm{Bcl}-2$ are probably not strictly linked to GSH amount in the cell [37]; however, it is likely that there are direct or indirect relationships between them. During therapy with etoposide or a camptothecin derivative $\mathrm{SN}-38$, cells with $\mathrm{Bcl}-2$ overexpression showed improved survival and developed drug resistance which probably involves glutathione. The experiments involving BSO have shown that as a result of glutathione levels reduction in cells with $\mathrm{Bcl}-2$ overexpression, the resistance to these drugs was completely eliminated [66]. GSH synthesis depletion using BSO disrupts the processes of drug transport from the cell; this is the most likely cause of cell sensitisation. It is also suspected that BSO may facilitate ROS accumulation in the cells, increasing the cytotoxic effect of these drugs.

\section{DEVELOPMENT DIRECTIONS OF STRATEGIES TO FIGHT GLUTATHIONE-RELATED DRUG-RESISTANCE}

The multidrug resistance phenomenon is common; however, although it is not inseparably associated with all types of cancer, it is the most important problem in chemotherapy of these diseases.

More thorough understanding of the mechanisms regulating the oxidoreductive status of the cell, based on the activity of antioxidant systems, may be useful for developing drugs to be used in anticancer therapy. The possibility of precise regulation of glutathione levels during therapy is likely to be an important factor affecting treatment efficacy. The results of the latest studies also indicate the possible contribution of leukotrienes in cancer pathogenesis processes. Studies are currently 
ongoing on the possible antileukotriene treatment which could support both therapy of cardiovascular diseases and cancer [42].

There are several strategies of fighting glutathione-related multidrug resistance. Most of the developed methods consist in $\gamma$-GCS expression inhibition and glutathione synthesis blocking. This objective can be achieved through:

1. the use of BSO - the irreversible block of glutathione synthesis increases the sensitivity to platinum compounds, alkylating agents, anthracyclines and arsenium trioxide. A problem with BSO therapy is to determine the appropriate dose to avoid toxicity against normal cells;

2. the use of the "hammerhead" ribozyme versus mRNA of $\gamma$-GCS and its hydrolysis. In vitro tests have shown that this method increases the sensitivity of cancer cells to cytostatics, most likely by disrupting the MRP1-dependent transport of the drugs;

3. the use of the anti-c-jun construct. The cJun transcription factor is associated with GCS expression, and its inhibition causes a reduction in GCS levels, and as a result, a reduction in glutathione concentrations in the cell. However, the block of a transcription factor can cause other consequences in humans which are difficult to predict.

In the case of many diseases including neurodegenerative diseases, diabetes, AIDS, low GSH levels are seen, causing a reduction in the cellular protective mechanisms. To increase treatment efficacy in these cases, it is necessary to increase glutathione levels. In the course of cancer diseases, on the contrary, high intracellular glutathione concentrations have been reported. To reduce the detoxification processes and the antioxidant defence of cancer cells, the effective therapeutic strategies should therefore involve simultaneous use of cytostatics and glutathione biosynthesis inhibitors [6]. The optimum therapy should also lead to a selective increase in GSH levels in normal cells to prevent the adverse effects of radiation therapy and chemotherapy.

\section{REFERENCES}

[1] ADLER V, YIN Z, FUCHS SY, BENEZRA M, ROSARIO L, TEW KD, PINCUS MR, SARDANA M, HENDERSON CJ, WOLF CR, DAVIS RJ, RONAI Z. Regulation.of JNي _. signaling. by 1999; 18: 1321-1334.

[2] ARRIGO AP. Gene expression and the thiol redox state. Free Radic Biol Med 1999; 27(9-10): 936-944.

[3] BAILEY HH. L-S,R-buthionine sulfoximine: historical development and clinical issues. Chem Biol Interact 1998; 111-112: 239-254. 
[4] BALLATORI N, KRANCE SM, MARCHAN R, HAMMOND CL. Plasma membrane glutathione transporters and their roles in cell physiology and pathophysiology. Mol Aspects Med 2009; 30(1-2): 1328.

[5] BALLATORI N, REBBEOR JF. Roles of MRP2 and oatp1 in hepatocellular export of reduced glutathione. Semin Liver Dis 1998; 18(4): 377-387.

[6] BILSKA A, KRAWCZYK A, WŁODEK L. Różne oblicza biologicznej roli glutationu. Postepy Hig Med Dosw 2007; 61: 438-453.

[7] BODA D, NÉMETH I, PINTÉR S. Surface tension, glutathione content and redox ratio of the tracheal aspirate fluid of premature infants with IRDS. Biol Neonate. 1998; 74(4): 281-288.

[8] BORST P, EVERS R, KOOL M, WIJNHOLDS J.The multidrug resistance protein family. Biochim Biophys Acta 1999; 1461(2): 347-357.

[9] CAI J, JONES DP. Superoxide in apoptosis. Mitochondrial generation triggered by cytochrome c loss. J Biol Chem 1998; 273(19): 11401-11404.

[10] COLE SP, DEELEY RG. Multidrug resistance mediated by the ATP-_.binding casassette transporter protein MRP. Bioessays 1998; 20(11): 931-940.

[11] COLE SPC, BHARDWAJ G, GERLACH JH, MACKIE JE, GRANT CE, ALMQUIST KC, STEWART AJ, KURZ EU, DUNCAN AMV, DEELEY RG. Overexpression of a transporter gene in a multidrugresistant human lung cancer cell line. Science 1992; 258: 1650-1654.

[12] DAUBEUF S, LEROY P, PAOLICCHI A, POMPELLA A, WELLMAN M, GALTEAU MM, VISVIKIS A. Enhanced resistance of HeLa cells to cisplatin by overexpression of $\gamma$-glutamyltransferase. Biochem Pharmacol 2002; 64 (2): 207-216.

[13] DEELEY RG, COLE SP. Substrate recognition and transport by multidrug resistance protein 1 (ABCC1). FEBS Lett 2006; 580(4): 1103-1111.

[14] DEMASI M, SHRINGARPURE R, DAVIES KJ. Glutathiolation of the proteasome is enhanced by proteolytic inhibitors. Arch Biochem Biophys 2001; 389(2): 254-63.

[15] DOROSHOW JH, AKMAN S, CHU FF, ESWORTHY S. Role of the glutathione-glutathione peroxidase. cycle in the cytotoxicity of the anticancer quinones. Pharmacol Ther 1990; 47(3): 359-367.

[16] EATON DL, HAMEL DM. Increase in gamma-glutamylcysteine synthetase activity as a mechanism for. butylated hydroxyanisole-mediated elevation of hepatic glutathione. Toxicol Appl Pharmacol 1994; 126(1): 145-149.

[17] FOJO T, BATES S. Strategies for reversing drug resistance. Oncogene 2003; 22(47): 7512-7523.

[18] GARTENHAUS RB, PRACHAND SN, PANIAQUA M, LI Y, GORDON LI. Arsenic trioxide cytotoxicity in steroid and chemotherapy-resistant myeloma cell lines: enhancement of apoptosis by manipulation of cellular redox state. Clin Cancer Res 2002; 8(2): 566-72.

[19] GATE L, PAUL J, BA GN, TEW KD, TAPIERO H. Oxidative stress induced in pathologies: the role of antioxidants. Biomed Pharmacother 1999; 53(4): 169-180.

[20] GENDZWIŁL A. Reaktywne formy tlenu i hiporeaktywność naczyń we wstrząsie septycznym. Część II Przeciwutleniacze i hiporeaktywność naczyń we wstrząsie septycznym. Pol Merk Lek 2007; XXIII(136): 284-287.

[21] HIPFNER DR, DEELEY RG, COLE SP. Structural, mechanistic and clinical aspects of MRP1. Biochim Biophys Acta 1999; 1461(2): 359-376.

[22] HWANG C, SINSKEY AJ, LODISH HF. Oxidized redox state of glutathione in the endoplasmic reticulum. Science 1992; 257( 5076): 1496-1502.

[23] JULIANO RL, LING VA. A surface glycoprotein modulating drug permeability in Chinese hamster ovary cell mutants. Biochim Biophys Acta 1976; 455: 152-162.

[24] KLATT P, LAMAS S. Regulation of protein function by S-glutathiolation in response to oxidative and nitrosative stress. Eur J Biochem 2000; 267(16): 4928-4944.

[25] KLEE S, NÜRNBERGER MC, UNGEMACH FR. The consequences of nitrofurantoin-induced oxidative stress in isolated rat hepatocytes: evaluation of pathobiochemical alterations. Chem Biol Interact 1994; 93(2): 91-102. 
[26] KOOL M, VAB DER LINDEN M, DE HAAS M, SCHEFFER GL, DE VREE JM, SMITH AJ, JANSEN G, PETERS GJ, PONNE N, SCHEPER RJ, ELFERINK RP, BAAS F, BORST P. MRP3, an organic anion transporter able to transport anti-cancer drugs. Natl Acad Sci U S A 1999; 96(12): 6914-9619.

[27] KRUH GD, BERLINSKY MGThe MRP family of drug efflux pumps. Oncogene 2003; 22: 7537-7552.

[28] LAI GM, MOSCOW JA, ALVAREZ MG, FOJO AT, BATES SF. Contribution of glutathione and glutathione-dependent enzymes in the reversal of adriamycin resistance in colon carcinoma cell lines. Int $\mathrm{J}$ Cancer 1991; 49(5): 688-695.

[29] LEWIS AD, HAYES JD, WOLF CR. Glutathione and glutathione-dependent enzymes in ovarian adenocarcinoma cell lines derived from a patient before and after the onset of drug resistance: intrinsic. differences and cell cycle effects. Carcinogenesis 1988; 9(7): 1283-1287.

[30] LOE DW, DEELEY RG, COLE SP. Characterization of vincristine transport by the M(r) 190,000 multidrug resistance protein (MRP): evidence for cotransport with reduced glutathione. Cancer Res 1998; 58(22): 5130-5136.

[31] LOE DW, OLESCHUK CJ, DEELEY RG, COLE SP. Structure-activity studies of verapamil analogs that modulate transport of leukotriene $\mathrm{C}(4)$ and reduced glutathione by multidrug resistance protein MRP1. Biochem Biophys Res Commun 2000; 275(3): 795-803.

[32] LORICO A, BERTOLA A, BAUM C, FODSTAD O, RAPPA G. Role of the Multidrug Resistance Protein 1 in protection from heavy metal oxyanions: investigations in vitro and in MRP1-deficient mice. Biochem Biophys Res Commun 2002; 291(3): 617-622.

[33] ŁUKASZEWICZ-HUSSAIN A. Rola glutationu i enzymów $\mathrm{z}$ nim związanych w procesach antyoksydacyjnych organizmu. Med Pr 2003; 54(5): 473-479.

[34] MANNA SK, KUO MT, AGGARWAL BB. Overexpression of gamma-glutamylcysteine synthetase suppresses tumor necrosis factor-induced apoptosis and activation of nuclear transcription factor-kappa $\mathrm{B}$. and activator protein-1. Oncogene 1999; 18(30): 4371-4382.

[35] MEIJERMAN I, BEIJNEN JH, SCHELLENS JHM. Combined action and regulation of phase II enzymes and multidrug resistance proteins in multidrug resistance in cancer. Cancer treatment reviews 2008; 34(6): 505-520.

[36] MEISTER A, ANDERSON ME. Glutathione. Annu Rev Biochem 1983; 52: 711-760.

[37] MEURETTE O, LEFEUVRE-ORFILA L, REBILLARD A, LAGADIC-GOSSMANN D, DIMANCHEBOITREL MT. Role of intracellular glutathione in cell sensitivity to the apoptosis induced by tumor necrosis factor \{alpha\}-related apoptosis-inducing ligand/anticancer drug combinations. Clin Cancer Res 2005; 11(8): 3075-3083.

[38] MORAN LK, GUTTERIDGE JM, QUINLAN GJ. Thiols in cellular redox signalling and control. Curr Med Chem 2001; 8(7): 763-772.

[39] MULLER M, MEUER C, ZAMAN GJR, BORST P, SCHEPER RJ,MULDER NH, DE VRIES EGE, JANSEN PLM. Overexpression of the gene encoding the multidrug Resistanceassociated protein results in increased ATP-dependent glutathione S-conjugate transport. Proc Natl Acad Sci USA 1994; 91: 1303313037.

[40] O'BRIEN M, KRUH GD, TEW KD. The influence of coordinate overexpression of glutathione phase II detoxification gene products on drug resistance. J Pharmacol Exp Ther 2000; 294(2): 480-487.

[41] OGUCHI H, KIKKAWA F, KOJIMA M, MAEDA O, MIZUNO K, SUGANUMA N, KAWAI M, TOMODA Y. Glutathione related enzymes in cis-diamminedichloroplatinum (II)-sensitive and-resistant human ovarian carcinoma cells. Anticancer Res 1994;14(1A): 193-200.

[42] OHD JF, NIELSEN CK, CAMPBELL J, LANDBERG G, LÖFBERG H, SJÖLANDER A. Expression of the leukotriene D4 receptor CysLT1, COX-2, and other cell survival factors in colorectal adenocarcinomas. Gastroenterology 2003; 124(1): 57-70.

[43] OZOLS RF, LOUIE KG, PLOWMAN J, BEHRENS BC, FINE RL, DYKES D, HAMILTON TC. Enhanced melphalan cytotoxicity in human ovarian cancer in vitro and in tumor-bearing nude mice by buthionine sulfoximine depletion of glutathione. Biochem Pharmacol 1987; 36(1): 147-153. 
[44] PALMER HJ, PAULSON KE. Reactive oxygen species and antioxidants in signal transduction and gene expression. Nutr Rev 1997; 55: 353-361.

[45] PAOLICCHI A, LORENZINI E, PEREGO P, SUPINO R, ZUNINO F, COMPORTI M, POMPELLA A. Extra-cellular thiol metabolism in clones of human metastatic melanoma with different gamma-glutamyl transpeptidase expression: implications for. cell response to. platinum-based drugs. Int $\mathrm{J}$ Cancer 2002 ; 97(6): 740-745.

[46] PAULUSMA CC, VAN GEER MA, EVERS R, HEIJN M, OTTENHOFF R, BORST P, OUDE ELFERINK RP. Canalicular multispecific organic anion transporter/multidrug resistance protein 2 mediates low-affinity transport of reduced glutathione. Biochem J 1999; 338(Pt 2): 393-401.

[47] PAYEN L, COURTOIS A, VERNHET L, GUILLOUZO A, FARDEL O. The multidrug resistanceassociated protein (MRP) is over-expressed and functional in rat hepatoma cells. Int J Cancer 1999; 81(3): 479-485.

[48] POMPELLA A, DE TATA V, PAOLICCHI A, ZUNINO F. Expression of gamma-glutamyltransferase in. cancer cells and its significance in drug resistance. Biochem Pharmacol 2006; 71(3): 231-238.

[49] PRIEBE W, KRAWCZYK M, KUO MT, YAMANE Y, SAVARAJ N, ISHIKAWA T. Doxorubicin- and daunorubicin-glutathione conjugates, but not unconjugated drugs, competitively inhibit leukotriene $\mathrm{C} 4$ transport mediated by MRP/GS-X pump. Biochem Biophys Res Commun 1998; 247(3): 859-863.

[50] REBBEOR JF, CONNOLLY GC, HENSON JH, BOYER JL, BALLATORI N. ATP-dependent GSH and glutathione S-conjugate transport in skate liver: role of an Mrp functional homologue. Am J Physiol Gastrointest Liver Physiol 2000; 279(2): G417-G425.

[51] REED JC. Bcl-2 family proteins: regulators of apoptosis and chemoresistance in hematologic malignancies. Semin Hematol 1997; 34(4 Suppl 5): 9-19.

[52] RISTOFF E, LARSSON A. Inborn errors in the metabolism of glutathione. Orphanet J Rare Dis 2007; 2 : 16-24.

[53] RODRIGUEZ JF, CORDERO J, CHANTRY C, GONZÁLEZ S, RIVERA C, FEBO I, COLÓN A, DÍAZ C. Plasma glutathione concentrations in children infected with human immunodeficiency virus. Pediatr Infect Dis J. 1998; 17(3): 236-241.

[54] SALERNO M, LOECHARIYAKUL P, SAENGKHAE C, GARNIER-SUILLEROT A. Relation between the ability of some compounds to modulate the MRP1-mediated efflux of glutathione and to inhibit the MRPl-mediated efflux of daunorubicin. Biochem Pharmacol 2004; 68(11): 2159-2165.

[55] SCHNEIDER E, HORTON J, YANG CH, NAKAGAWA M, COWAN KH. Multidrug resistanceassociated protein gene overexpression and reduced drug sensitivity of topoisomerase II in a human breast carcinoma MCF-7 cell line selected for etoposide resistance. Cancer Res 1994; 54: 152-158.

[56] SCHULZ JB, LINDENAU J, SEYFRIED J, DICHGANS J. Glutathione, oxidative stress and neurodegeneration. Eur J Biochem 2000; 267(16): 4904-4911.

[57] SEN CK, PACKER L. Antioxidant and redox regulation of gene transcription. FASEB-J 1996; 10(7): 709720

[58] TANIGUCHI M, YASUTAKE A, TAKEDOMI K, INOUE K. Effects of N-nitrosodimethylamine (NDMA) on the oxidative status of rat liver. Arch Toxicol 1999; 73(3):141-146.

[59] TEODORI E, DEI S, SCAPECCHI S, GUALTIERI F. The medicinal chemistry of multidrug resistance (MDR) reversing drugs. Il Farmaco 2002; 57(5): 385-415

[60] TEW KD. Glutathione-associated enzymes in anticancer drug resistance. Cancer Res 1994; 54: 43134320.

[61] TIPNIS SR, BLAKE DG, SHEPHERD AG, MCLELLAN LI. Overexpression of the regulatory subunit of gamma-glutamylcysteine synthetase in HeLa cells increases gamma-glutamylcysteine synthetase activity and confers drug resistance. Biochem J 1999; 337(Pt 3): 559-566.

[62] TOWNSEND DM, TEW KD. The role of glutathione-S-transferase in anti-cancer drug resistance. Oncogene 2003; 22(47): 7369-7375.

[63] VAHRMEIJER AL, HOETELMANS RW, MULDER GJ, SCHUTRUPS J, VAN VLIERBERGHE RL, VAN DE VELDE CJ, VAN DIERENDONCK JH. Development of resistance to glutathione depletion- 
induced cell death in CC531 colon carcinoma cells: association with increased expression of bcl-2. Biochem Pharmacol 2000; 59(12): 1557-1562.

[64] VAN BLADEREN PJ. Glutathione conjugation as a bioactivation reaction. Chem Biol Interact 2000; 129 : 61-76.

[65] VERSANTVOORT CH, BROXTERMAN HJ, BAGRIJ T, SCHEPER RJ, TWENTYMAN PR. Regulation by glutathione of drug transport in multidrug-resistant human lung tumour cell lines $\overline{\text { overexpressing multidrug resistance-associated protein. Br J Cancer 1995; }} \overline{72(1)} \overline{82-89}$.

[66] YOSHIDA A, TAKEMURA H, INOUE H, MIYASHITA T, UEDA T. Inhibition of glutathione synthesis overcomes Bcl-2-mediated topoisomerase inhibitor resistance and induces nonapoptotic cell death via mitochondrial-independent pathway. Cancer Res 2006; 66(11): 5772-5780.

[67] YOUNG LC, CAMPLING BG, VOSKOGLOU-NOMIKOS T, COLE SP, DEELEY RG, GERLACH JH. Expression of multidrug resistance protein-related genes in lung cancer: correlation with drug response. Clin Cancer Res 1999 Mar; 5(3): 673-680.

[68] ZAMAN GJ, LANKELMA J, VAN TELLINGEN O, BEIJNEN J, DEKKER H, PAULUSMA C, OUDE ELFERINK RP, BAAS F, BORST P. Role of glutathione in the export of compounds from cells by the multidrug-resistance-associated protein. Proc Natl Acad Sci U S A 1995; 92(17): 7690-7694.

[69] ZEMBRON-ŁACNY A., SZYSZKA K., SOBAŃSKA B., PAKUŁA R. Przemiana glutationu we krwi biegaczy średniodystansowych. Borgis - Nowa Medycyna, 1999; 7: 20-22.

Corresponding author: Ewa Karwicka

Work address: Biochemistry and Biopharmaceuticals Department, National Medicines Institute, 30/34 Chelmska Street, 00-725 Warsaw

Phone: (0-22) 8413991 ext. 302

Home address: 21 Sieniawska Street, 04-939 Warsaw

e-mail address: ewa@il.waw.pl 